\title{
Vinyl Ester Resin Modified with Acrylated Epoxidised Soybean (AESO) and Linseed (AELO) Oils: Effect of Additional Urethane Crosslinking
}

\author{
S. Grishchuk ${ }^{1}$ and J. Karger-Kocsis ${ }^{2,3 *}$ \\ ${ }^{1}$ Institut für Verbundwerkstoffe GmbH (Institute for Composite Materials), Kaiserslautern University of Technology, \\ D-67663 Kaiserslautern, Germany \\ ${ }^{2}$ Department of Polymer Engineering, Budapest University of Technology and Economics, Muegyetem rkp. 3, H-1111 \\ Budapest, Hungary \\ ${ }^{3}$ MTA-BME Research Group for Composite Science and Technology, Muegyetem rkp. 3., H1111 Budapest, Hungary
}

Received: 21 March 2016, Accepted: 14 June 2016

\section{SUMMARY}

\begin{abstract}
Bisphenol A-based vinyl ester resin (VE) was modified with acrylated epoxidised soybean and linseed oils (AESO and AELO, respectively) in $10 \mathrm{wt} . \%$. The double bond/epoxy ratio in these functionalised vegetable oils was practically the same, i.e. 30/70\%, allowing us to deduce effects caused by the different unsaturations in the parent oils. The crosslink density of the resins was enhanced by adding polyisocyanate. The glass transition temperature $\left(\mathrm{T}_{\mathrm{g}}\right.$ ) of the hybrids was determined by differential scanning calorimetry (DSC) and dynamic mechanical thermal analysis (DMTA). Resistance to thermal degradation was assessed by thermogravimetric analysis (TGA). The fracture toughness and energy ( $\mathrm{K}_{\mathrm{c}}$ and $\mathrm{G}_{\mathrm{c}}$, respectively) were determined on compact tension specimens at room temperature. Incorporation of AESO and AELO reduced the $\mathrm{T}_{\mathrm{g}}$ of VE along with slight reductions in the $\mathrm{K}_{\mathrm{c}}$ and $\mathrm{G}_{\mathrm{c}}$ data. The $\mathrm{T}_{\mathrm{g}}$ reduction was less for AELO than AESO which was attributed to the higher functionality of AELO compared to AESO. Urethane crosslinking of VE (VEUH) prominently enhanced the $\mathrm{T}_{\mathrm{g}}$. Modification of VEUH with AES(L)O enhanced the $\mathrm{T}_{\mathrm{g}}$ due to additional crosslinks. Urethane hybridisation was associated with a strong decrease in both $\mathrm{K}_{c}$ and $\mathrm{G}_{c}$ compared to those of the parent VE. $\mathrm{K}_{c}$ and $\mathrm{G}_{c}$ of VEUH did not change practically as a function of blending with $\mathrm{AES}(\mathrm{L}) \mathrm{O}$. Incorporation of $\mathrm{AES}(\mathrm{L}) \mathrm{O}$ reduced the resistance to thermal degradation of both VE and VEUH.
\end{abstract}

Keywords: Vinylester resin, Acrylated epoxidized soybean oil, Acrylated epoxidized linseed oil, Urethane crosslinking, Fracture toughness, Thermo-mechanical behavior

\section{INTRODUCTION}

Environmental concerns (global warming, waste disposal, "carbon footprint") and depletion of fossil fuels force a change in feedstocks from fossil types to renewable ones. Among the renewable materials plant oils can be considered as most promising alternative feedstock for the chemical and polymer industries ${ }^{1}$. Plant or vegetable oils (VO) are predominantly triglycerides composed of a glycerol centre to which three fatty acids are

Corresponding author: karger@pt.bme.hu

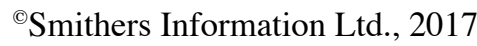

connected via ester linkages. The chain length and unsaturation level (number of double bonds) of the fatty acids are different for various plant oils ${ }^{2-3}$. Those having high level of unsaturation, such as soybean (SO) and linseed oils (LO), are most suited polymer "precursors". They are several active sites in triglycerides capable for chemical reactions to produce polymerisable entities as stated by Wool et al. ${ }^{2}$. In this pioneering work Wool's group outlined different chemical pathways for the functionalisation and follow- up polymerisation of plant oils. This has been served as guideline for the research in the academia worldwide.

Though the reactivity of plant oils can be enhanced by different ways, possibilities offered by the initial double bonds attracted mostly the interest of researchers. The unsaturations can be easily converted to epoxy groups ${ }^{2,3}$ and the resulting epoxidised plant oils are commercially available and widely used, for example as plasticisers for polyvinyl chloride. Many attempts were already made to explore the property profile of thermosets and related composites from epoxidised plant oils alone ${ }^{47}$ or in combination with petrochemical- 
based resins ${ }^{8-11}$. Converting the epoxy to vinyl functionalities by reacting with acrylic acid is a straightforward strategy to enhance the reactivity (formation of quasi-terminal double bonds) $)^{2,3,12-13}$, thereby widening the use of plant oils. The related acrylated epoxidised vegetable oils (AEVOs), suitable for free radical induced or UVinduced (co)polymerisation reactions, are also commercially available. AEVOs were often converted into thermosets, including foams, nano- and traditional composites, via various (co) polymerisation/curing methods ${ }^{13-20}$. AEVOs can be further functionalised, for example via maleination ${ }^{2-3,12-13}$.

Vinyl ester (also termed to as epoxy acrylates) resins (VE) outperform the cheaper unsaturated polyesters with respect to mechanical properties and chemical resistance. To make VE "greener" basically two main strategies may be followed. One of them is related to the reduction or replacement of the crosslinking styrene monomer (for example via incorporation of acryl functionalised fatty acids ${ }^{21-22}$ ) while the other addresses the replacement or dilution of the parent VE resin. As far as the latter concerns, VE was already blended with AESO in the whole concentration range ${ }^{23}$. With increasing amount of AESO the stiffness, strength and glass transition temperature $\left(\mathrm{T}_{\mathrm{g}}\right)$ of the hybrids decreased. The reduction was less when phthalic anhydride was additionally used. Note that the latter should enhance the crosslink density through coupling the $-\mathrm{OH}$ functional groups of VE and AESO ( $c f$. Figure 1).

It has been demonstrated by Lu et al. ${ }^{24}$ that with increasing crosslink density of functionalised soybean oil-based thermosets their stiffness and $\mathrm{T}_{\mathrm{g}}$ can be markedly increased. Accordingly, enhancement of the crosslink density of hybrid thermosets composed of AEVOs and VE is of paramount importance to avoid the dropin the thermo-mechanical properties. The $-\mathrm{OH}$ functionalities of AEVOs can be coupled with the secondary $-\mathrm{OH}$ groups of the $\mathrm{VE}$ (cf. Figure 1) making use of the urethane chemistry ${ }^{25-28}$. This approach yielded the desired $\mathrm{T}_{\mathrm{g}}$ improvement and resulted in the commercialisation of vinylester-urethane hybrid resins (VEUH) in the 1990's. Interestingly this urethane coupling route was not yet followed for hybrids composed of VE and AEVOs. The only publication covering this aspect was dealing with VE-based bulk moulding compounds ${ }^{29}$.

Figure 1. Molecular structures of acrylated epoxidised soybean (AESO) and linseed oils (AELO) and bisphenol A-based VE

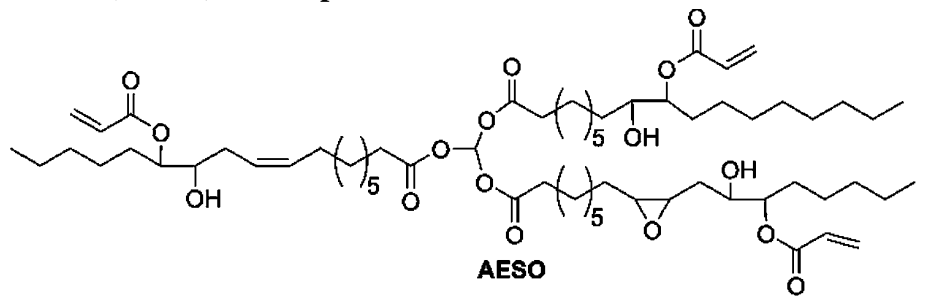

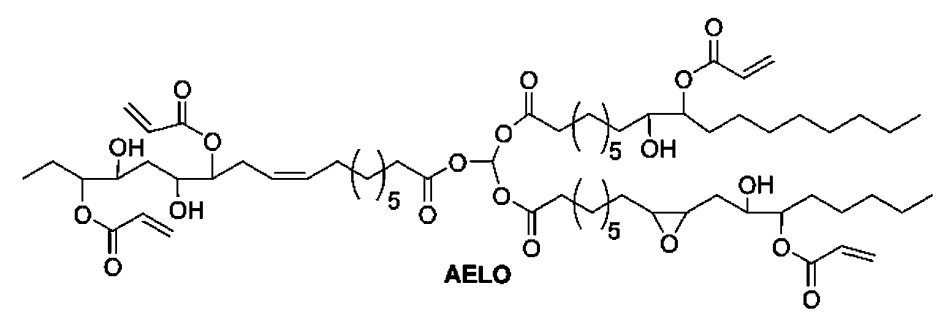<smiles>C=C(C)C(=O)OCC(O)COc1ccc(C(C)(C)c2ccc(OCC(O)COc3ccc(C(C)(C)c4ccc(C(C)(C)c5ccc(OCC(O)COC(=O)C(=C)C)cc5)cc4)cc3)cc2)cc1</smiles>

On the other hand, reports are available on the combined use of VE and AEVO, especially as matrix materials for composites with bio-based (vegetable fibres) reinforcements ${ }^{30-31}$. In case of composites with VE/AEVO matrix possible effects of the type and characteristics (functionalisation) of AEVO can hardly be studied owing to the "masking" by the reinforcements. Therefore investigations should focus on hybrids composed of VEandAEVOs of different characteristics. This is the right place to underline that the above treatise strictly related to VE-based systems thereby disregarding results available on unsaturated polyester resin systems.

Accordingly, this work was aimed at studying the effects of acrylated epoxidised soybean (AESO) and linseed (AELO) oils on the thermal and fracture mechanical properties of VE resin with and without further modification with polymeric diisocyanate. AESO and AELO were incorporated into VE in $10 \mathrm{wt}$ \% $\%$ based on the observation that this kind of dilution does not require any change in the curing recipe. In order to get further information on how the initial difference in the unsaturation levels between SO and LO (average double bonds per molecule 4.6 and 6.6 for SO and LO, respectively ${ }^{2}$ ) affect the above properties functionalised versions of similar acrylation/epoxidation ratio (ca. 30/70) were selected.

\section{EXPERIMENTAL}

\subsection{Materials}

AESO and AELO were obtained from professor M. Döring (KIT, Karlsruhe, Germany). According to ${ }^{1} \mathrm{H}-\mathrm{NMR}$ spectroscopy both SO and LO were highly epoxidised before catalytic acrylation with acrylic acid. The latter was introduced in small surplus with respect to the required amount to avoid eventual effects of acrylic acid residue on the curing with VE. On the other hand, acrylation of ESO and 
ELO occurred only partly. According to NMR spectroscopic results the acryl/epoxy groups' ratio was at about $30 / 70 \%$ for both oils. It is noteworthy, that by contrast to epoxidation of plant oils, their subsequent acrylation is never complete ${ }^{12,32}$.

Styrene diluted bisphenol-A type VE (Daron-XP-45-A2 from DSM Composite Resins AG, Schaffhausen, Switzerland) with a density of $1.080 \mathrm{~g} /$ $\mathrm{ml}$, viscosity of about $200 \mathrm{mPa} \cdot \mathrm{s}$ and styrene content of about $30 \%$ was chosen for this study. AESO and AELO were introduced in VE and VEUH compositions in $10 \mathrm{wt} . \%$. As a urethane crosslinker, polymeric 4,4'-methylenediphenyl diisocyanate (PMDI; Lupranat ${ }^{\circledR M} 20 \mathrm{~S}, \mathrm{BASF}$, Ludwigshafen, Germany) served which was added in 40 part per hundred resin (phr) amount. Adding PMDI in this amount is rather an engineering than scientific approach because the hydroxyl contents of VE and AEVOs were not determined. This approach can be reasoned also by the fact that the isocyanate groups may be involved in other reactions than solely urethane formation, as discussed later.

The preparation of the hybrid resins was as follows. VE and the AE oils were mixed together at ambient temperature at 800 revolutions per minute (rpm) for $5 \mathrm{~min}$. Then, $1.5 \mathrm{phr}$ of dibenzoyl peroxide (Akzo Nobel, Düren, Germany) and $0.15 \mathrm{phr}$ of accelerator $\mathrm{N}, \mathrm{N}$-diethylaniline (NL100 of Akzo Nobel, Düren, Germany) were introduced in VE composition which were dissolved in the mixtures at similar stirring speed. The resins were degassed in vacuum desiccator. VEUH was prepared by introducing PMDI without using accelerator. The mixtures of VE and PMDI were mixed for additional $3 \mathrm{~min}$ at $800 \mathrm{rpm}$. All hybrids were degassed and poured into open Teflon ${ }^{\circledast}$ moulds. Rectangular $\left(100 \times 10 \times 4 \mathrm{~mm}^{3}\right.$, length $\times$ width $x$ thickness) and compact tension (CT) specimens $\left(35 \times 35 \times 4 \mathrm{~mm}^{3}\right.$, length $\times$ width $\times$ thickness) were prepared.
For the crosslinking of the systems the following curing regime was set: room temperature for $1 \mathrm{~h}, 50^{\circ} \mathrm{C}$ for $15 \mathrm{~min}$, $80^{\circ} \mathrm{C}$ for $30 \mathrm{~min}, 140^{\circ} \mathrm{C}$ for $30 \mathrm{~min}$, and finally $180^{\circ} \mathrm{C}$ for $1 \mathrm{~h}$. The moulds were then cooled to ambient temperature overnight and the specimens removed for testing.

\subsection{Testing}

The thermo-mechanical performance of the cured samples was studied by differential scanning calorimetry (DSC) and dynamic-mechanical thermal analysis (DMTA), respectively. DSC traces were recorded by a DSC 821 device of Mettler Toledo (Gießen, Germany) at $10{ }^{\circ} \mathrm{C} / \mathrm{min}$ heating rate in the temperature range of -100 to $250{ }^{\circ} \mathrm{C}$. For the $\mathrm{T}_{\mathrm{g}}$ of the resins the mid-point of the glass transition step was considered.

DMTA traces (storage modulus, E'; and the mechanical loss factor, $\tan \delta$ $v s$. temperature) were determined in a DMA Q800 device of TA Instruments (New Castle, DE, USA) on rectangular specimens $\left(60 \times 10 \times 3 \mathrm{~mm}^{3}\right.$; length $\mathrm{x}$ width $\mathrm{x}$ thickness) in 3-point bending configuration (span length: $50 \mathrm{~mm}$ ) at $1 \mathrm{~Hz}$ frequency an using oscillation amplitude of $50 \mu \mathrm{m}$. The scan rate in the broad temperature range $(\mathrm{T}=$ $-100 \ldots>+250{ }^{\circ} \mathrm{C}$ ) was $1{ }^{\circ} \mathrm{C} / \mathrm{min}$.

The fracture toughness $\left(\mathrm{K}_{\mathrm{c}}\right)$ and fracture energy $\left(G_{c}\right)$ were determined on notched CT specimens following the ISO 13586-1 standard (ESIS protocol). The sawn notch of the CT specimens was sharpened by blade tapping prior to testing in a Zwick 1445 machine (Zwick, Ulm, Germany) at room temperature with a $\mathrm{v}=1 \mathrm{~mm} / \mathrm{min}$ crosshead speed.

The cured resins were subjected to thermogravimetric analysis (TGA) in a DTG-60 device of Shimadzu Deutschland GmbH (Duisburg, Germany). The TGA experiments were conducted under nitrogen atmosphere $(30 \mathrm{ml} / \mathrm{min}$ flow rate) in the temperature range $\mathrm{T}=$ $+25{ }^{\circ} \mathrm{C} . . .+600{ }^{\circ} \mathrm{C}$ with heating rate $20{ }^{\circ} \mathrm{C} / \mathrm{min}$.

\section{RESULTS AND DISCUSSION}

Figure 2a and b display the DSC traces of the VE and VEUH modified with AESO and AELO, respectively.

The traces in Figure 2a indicate that both AESO and AELO reduce the $T_{g}$ values of VE. This is due to the fact that rather long and flexible segments appear in the crosslinked structure owing to the hybridisation with AEVOs. This is shown schematically in Figure 3. By contrast, the $T_{g}$ values slightly increase in case of VEUH when hybridised with AEVO ( $c f$. Figure 2b).

Further, the DSC results ( $c f$. Figure 2 and Table1) indicate that AELO caused somewhat smaller $\mathrm{T}_{\mathrm{g}}$ reduction than AESO in case of VE. Similarly, the positive effect of AELO on the $T_{g}$ of VEUH is also somewhat higher than that of AESO. This can be traced to the difference in the initial unsaturations between AELO (higher) and AESO (lower). Accordingly, AELO produces a slightly higher crosslink density in both VE and VEUH than AESO. Recall that the $\mathrm{T}$ values of the $\operatorname{AES}(\mathrm{L})$ O-modified VEŬH hybrids are above that of the corresponding reference. Attention should be paid to the fact that incorporation of PMDI was associated with a prominent increase in $\mathrm{T}_{\mathrm{g}}(c f$. Figure 2 and Table1). VEUHexhibited a T almost $115^{\circ} \mathrm{Chigher}$ than the parent VE. This finding confirms results of our earlier works $s^{26,28}$. The related difference was even higher $\left(125-130{ }^{\circ} \mathrm{C}\right)$ in case of AEVO-modified VEUH systems (cf. Table 1).

In Figure4 the DMTAtraces, viz. storage modulus (E') and mechanical loss factor $(\tan \delta)$ as a function of temperature $(\mathrm{T})$ are depicted for the VE (Figure 4a) and VEUH modified with AESO and AELO (Figure 4b), respectively. 
Considering the $\mathrm{E}^{\prime} v s$. $\mathrm{T}$ traces for the VE systems in Figure 4a one can recognise that the storage modulus of VE decreases owing to hybridisation with AESO and AELO compared to the reference VE in the whole temperature range. This, in line with our former results $^{23}$, indicates that a less tightly crosslinked structure developed in presence of the AEVOs ( $c f$. scheme in Figure 3). Modification with AESO decreased the storage modulus a little more than AELO. Again, this can be attributed to differences in the overall functionalisation levels of AELO and AESO. Higher reactivity and content of double bonds in LO, compared to SO, result in higher content of functional groups (acryl and epoxy). This yields higher crosslinking density and thus

Figure 2. DSC traces of VE (a) and VEUH (b) modified with 10 wt.\% AESO and AELO

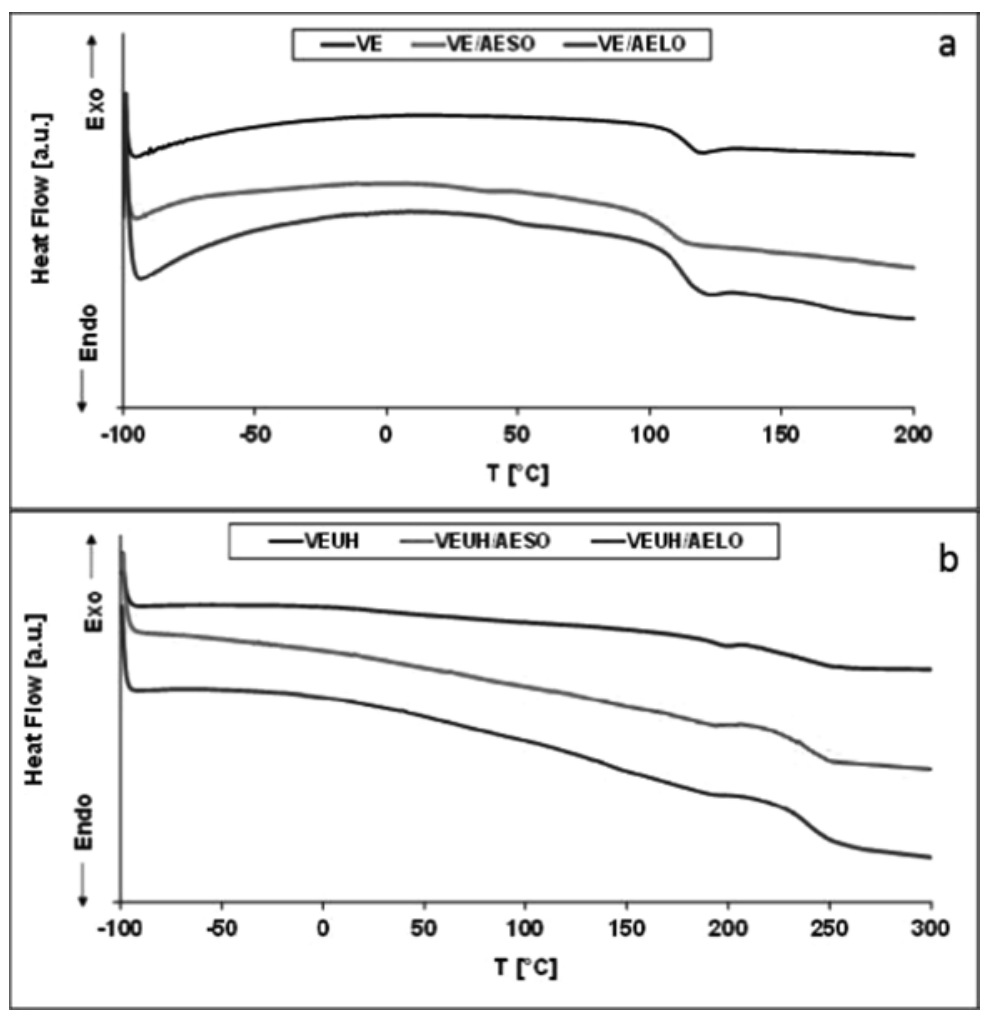

smaller E' decrease in VE/AELO than in VE/AESO. The tan $\delta v s$. T traces of the VE-based hybrids show a rather sharp $\alpha$-relaxation $\left(\mathrm{T}_{\mathrm{g}}\right)$ peak. This hints for good compatibility between $\mathrm{VE}$ and $\mathrm{AE}(\mathrm{S}) \mathrm{LO}$ that was claimed in our former work, too ${ }^{23}$. This $\alpha$-peak shifts to lower temperatures due to the modification with AE oils. This shift in the DMTA-related $T_{g}$ values is less for AELO than AESO that can be reasoned by differences in the crosslinked networks as disclosed before. The related $\mathrm{T}_{\mathrm{g}}$ values, listed also in Table 1, are in harmony with those deduced from DSC tests.

Having a look at the DMTA response of the VEUH-based systems in Figure 4b several striking features can be observed. Urethane crosslinking shifted the E'vs. T curves toward higher temperatures compared to VE. The related shift depends on the molecular structure and functionality of the VE and polyisocyanate ${ }^{26}$. Difference between the modifications with AESO and AELO in respect to the E' is that the E'vs. T curve of the AELO modified VEUH runs above that of the AESOmodified one in a given temperature range ( $c f$. Figure 4b). The $\alpha$-relaxation transition $\left(\mathrm{T}_{\mathrm{g}}\right.$ ) peak of the VEs was much higher than the corresponding VEUHs ( $c f$. Figure 4a and $\mathbf{4 b}$ ). This, reported also in Ref. 26, is due to the tighter crosslink structure as argued before. Moreover, hybridisation with

Figure 3. Effects of AEVOs on the crosslinked structures of VE and VEUH, schematically Note: circle denotes oxazolidone formation ${ }^{33}$ between the epoxy group of AEVO and isocyanate of PMDI

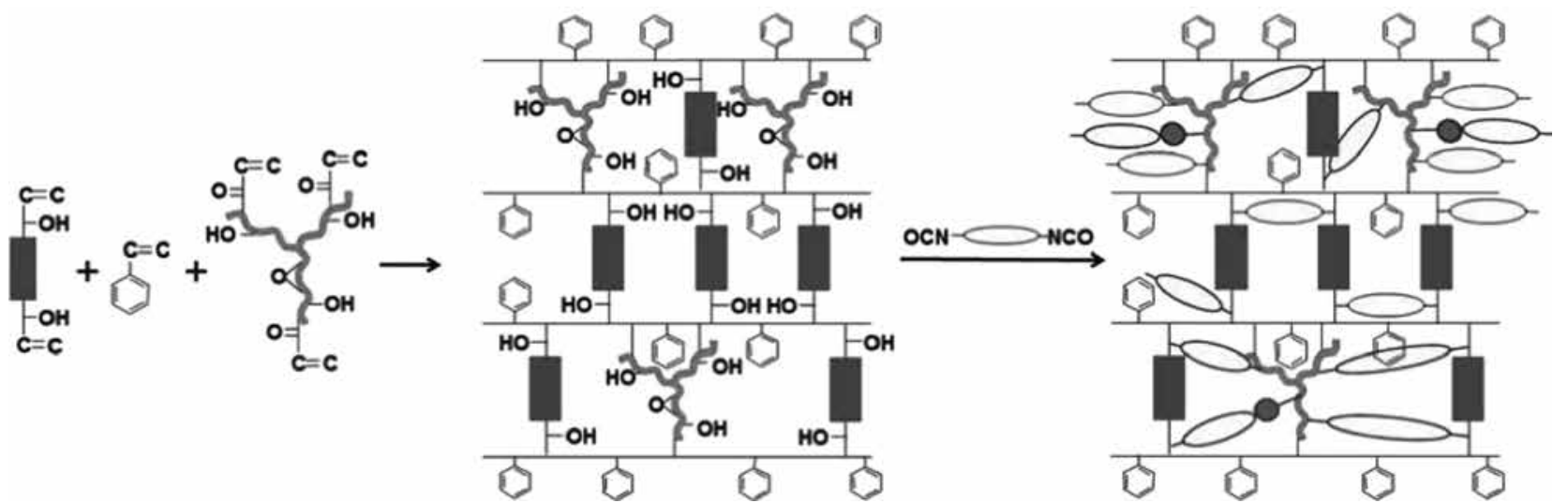


AEVOs did not reduce the $\mathrm{T}$, just the opposite tendency occurred $-c f$. Figure $4 \mathbf{b}$ and Table 1 . This can be explained by the additional crosslinking possibilities between the residual epoxy groups of the AVEOs with - NCO groups of PMDI, -NH- groups of the urethane linkages and even residual $-\mathrm{OH}$ groups of the $\mathrm{VE}$ and AEVOs ( $c f$. Figure 3). On the other hand, the $\alpha$-relaxation transition is broader for the VEUH- than for the VE-based versions. This is linked with the development of a more heterogeneous network structure involving PMDI segments ( $c f$. Figure 3). Attention should be paid to the fact that PMDI not only couples VE and AEVO with each other via the related - $\mathrm{OH}$ groups but may react with the $-\mathrm{OH}$ groups within each of them. Further, the secondary amine groups of the urethane linkages may react with the epoxy groups of the AEVO whereby tightening the network. Moreover, reactions between the secondary - $\mathrm{OH}$ groups of $\mathrm{VE}$ and AEVO and epoxy groups of the latter ( $c f$.Figure 1) cannot be excluded either. Oxazolidone may also form in the reaction between the epoxy groups of AEVOs and isocyanate of $\mathrm{PMDI}^{33}$ ( $c f$. Figure 3). Due to the above reactions an inhomogeneous network forms which may result even in phase separation ${ }^{23}$. This is the reason of the broadening of the $\alpha$-relaxation and appearance of the f3'-one (sub- $T_{\mathrm{g}}$ relaxation) in the form of a shoulder at $\mathrm{T} \approx 50^{\circ} \mathrm{C}$ in Figure 4 . Similar results were obtained for VE/ AESO series ${ }^{23}$. It is noteworthy that a shallow f3-relaxation can be found at $\mathrm{T} \approx-80{ }^{\circ} \mathrm{C}$ that can be assigned to relaxation of aromatic moieties in the structure of VE and PMDI. The DMTA results show the same tendency as the DSC data (Table 1). Note that for all systems only one $T_{g}$ was detected indicating a high compatibility between the VE and AEVOs.

The modified VE-based hybrids showed slightly reduced $\mathrm{K}_{\mathrm{c}}$ and $\mathrm{G}_{\mathrm{c}}$ values compared to the corresponding reference. The reduction was again smaller for the AELO- than for the

Figure 4. DMTA traces of VE (a) and VEUH (b) modified with 10 wt.\% AESO and AELO
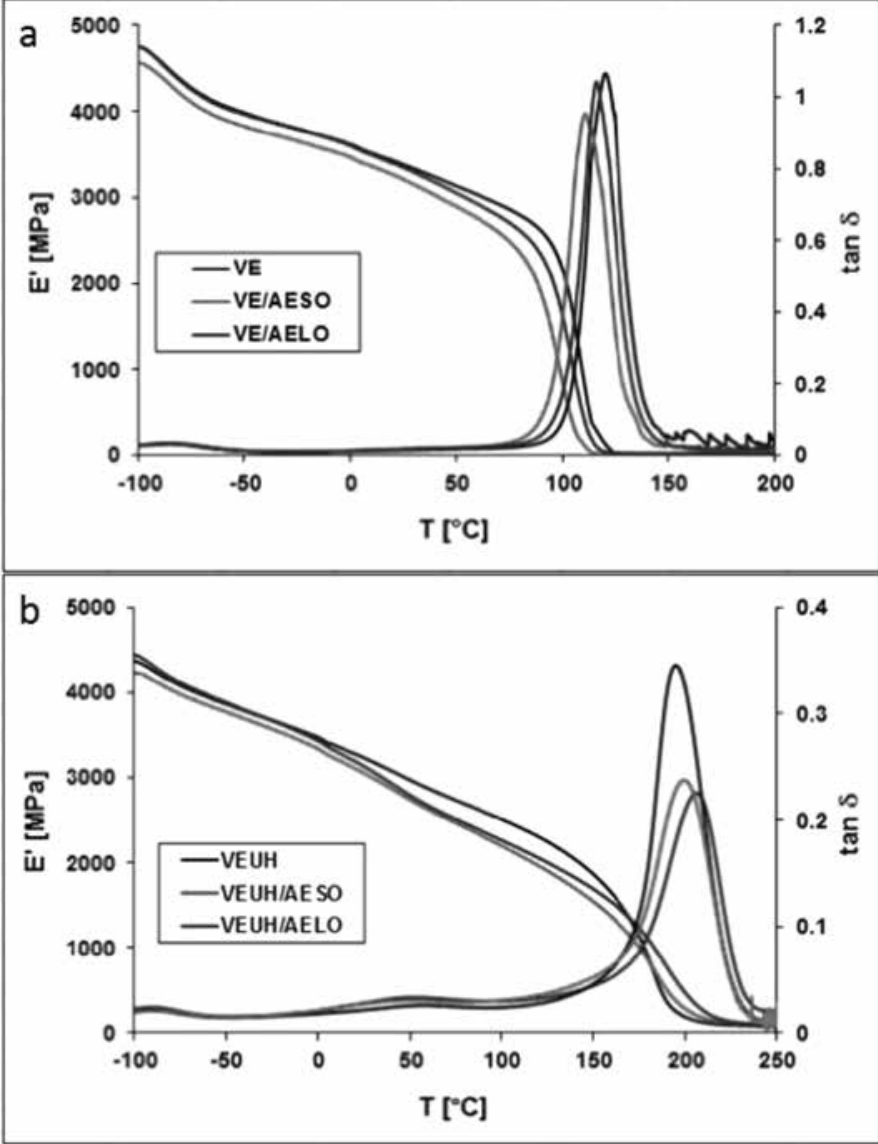

AESO-modified systems $-c f$. Figure 5 and Table 1. The VEUH and its hybrids withAEVOs were more brittle than the VEcounterparts. The corresponding $\mathrm{K}_{c}$ and $\mathrm{G}_{\mathrm{c}}$ data were almost half of those of the VEs ( $c f$. Figure 5 and Table 1). Practically the same results were found for a novolac-based VE which has been hybridised with a novolacbased polyisocyanate ${ }^{26}$. Accordingly, VEUH possesses a tighter crosslinked structure than VE. Recall that this was evidenced by the DSC and DMTA results already and explained by the scheme in Figure 3. It is worth of noting that the above linear elastic fracture mechanical parameters decrease with increasing crosslink density (increasing molecular weight between crosslinks) - albeit via different functions ${ }^{26,34-35}$. An interesting result is that modification of VEUH with AEL(S)O practically did not influence the $\mathrm{K}_{\mathrm{c}}$ and $\mathrm{G}_{\mathrm{c}}$ data. This is not fully unexpected because the stiffness of the related hybrids is practically the same at room temperature ( $c f$. Figure $\mathbf{4 b}$ ), and $\mathrm{K}_{\mathrm{c}}$ and $\mathrm{G}_{\mathrm{c}}$ are interrelated through the stiffness (E-modulus).

In order to check the influence of the AE-functionalised oils on the thermal stability of the obtained VE- and VEUH-based systems TGA investigations were performed. 5\% of weight loss (T5\%) was selected as criteria of thermostability. We have to note that VE-based systems have better thermostability, than VEUHs (Table 1). Modification with 10 wt.\% AEVOs slightly decreased the thermal resistance of the corresponding hybrid resins based on the above criterion. On the other hand, the char content of the VEUH and its hybrids was considerably higher than the VE counterparts. This can be 
Table 1. $T_{g}\left(D S C\right.$, DMTA), thermal stability $\left(T_{5 \%}\right)$, ash content and linear elastic fracture mechanical parameters $\left(K_{c}, G_{c}\right)$ for the AESO- and AELO-modified VE and VEUH resins

\begin{tabular}{|l|c|c|c|c|c|c|}
\hline & VE & VE/AESO & VE/AELO & VEUH & VEUH/AESO & VEUH/AELO \\
\hline $\mathrm{T}_{\mathrm{g}}(\mathrm{DMA}),\left[{ }^{\circ} \mathrm{C}\right]$ & 120 & 111 & 116 & 197 & 202 & 207 \\
\hline $\mathrm{T}_{\mathrm{g}}(\mathrm{DSC}),\left[{ }^{\circ} \mathrm{C}\right]$ & 114 & 106 & 113 & 230 & 236 & 238 \\
\hline & & & & & & \\
\hline $\mathrm{T}_{5 \%},\left[{ }^{\circ} \mathrm{C}\right]$ & 415 & 405 & 399 & 366 & 359 & 353 \\
\hline Char yield at $600{ }^{\circ} \mathrm{C},[\%]$ & 3.5 & 3.6 & 4.1 & 14.8 & 10.5 & 13.4 \\
\hline & & & & & & \\
\hline $\mathrm{K}_{\mathrm{c}},\left[\mathrm{MPa} \cdot \mathrm{m}^{1 / 2}\right]$ & $0.87 \pm 0.11$ & $0.64 \pm 0.03$ & $0.79 \pm 0.03$ & $0.50 \pm 0.02$ & $0.44 \pm 0.03$ & $0.46 \pm 0.03$ \\
\hline $\mathrm{G}_{\mathrm{c}},\left[\mathrm{kJ} \cdot \mathrm{m}^{-2}\right]$ & $0.41 \pm 0.09$ & $0.36 \pm 0.07$ & $0.40 \pm 0.07$ & $0.22 \pm 0.03$ & $0.19 \pm 0.03$ & $0.18 \pm 0.01$ \\
\hline
\end{tabular}

Figure 5. $\mathrm{K}_{\mathrm{c}}$ and $\mathrm{G}_{\mathrm{c}}$ data for the AESO- and AELO-modified VE and VEUH resins

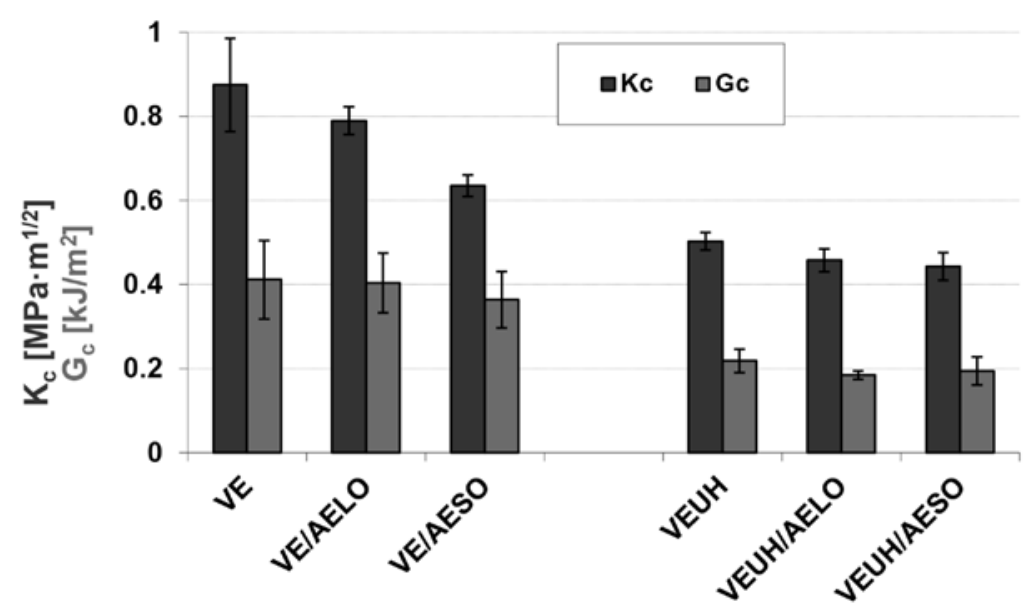

ascribed to the charring capability of nitrogen-containing compounds, which is exploited in many flame-retardant systems $^{36}$.

\section{CONCLUSIONS}

This work devoted to study the effects of vinylester resin (VE) hybridisation with acrylated epoxidised soybean (AESO) and linseed oils (AELO) and polymeric 4,4'-methylenediphenyl diisocyanate (PMDI). The acrylation/ epoxidation ratio of both AESO and AELO was similar $(\approx 30 / 70 \%)$ based on which information could be deduced on the difference in the initial unsaturation (reactivity) between SO and LO. The AE-functionalised oils were incorporated in $10 \mathrm{wt} . \%$ in the $\mathrm{E}$ and VEUH resins. The results achieved can be summarised as follows:

- VE: incorporation of AES(L)O reduced the $\mathrm{T}_{\mathrm{g}}$ according to DSC and DMTA results. The storage modulus was also reduced in the temperature range studied by this modification. Accordingly, AES(L) $\mathrm{O}$ worked as active diluents in VE thereby reducing the crosslink density. AELO yielded smaller reduction than AESO due to its initial higher unsaturation level. Modification with these AE-oils had a small negative effect on the fracture toughness $\left(\mathrm{K}_{\mathrm{c}}\right)$ and energy $\left(G_{c}\right)$ data, as well as on the thermal stability.

- VEUH: modification with PMDI prominently increased the $\mathrm{T}_{\mathrm{g}}$ of the parent VE. Incorporation of AES(L)O slightly enhanced the $\mathrm{T}_{\mathrm{g}}$ according to DSC and DMTA results. This was traced to the formation of additional crosslinks due to reactions between residual functional groups (hydroxyl, epoxy) of AEVOs with those of VE(hydroxyl), PMDI (isocyanate) and urethane linkages (-NH-) developed. Modification with AES(L)O reduced the storage modulus only above $\mathrm{T} \approx 50{ }^{\circ} \mathrm{C}$ compared to the reference. This was attributed to the development of an inhomogeneous network with different segmental motions based on DMTA results. Incorporation of the AEVOs had no effect on the $\mathrm{K}_{\mathrm{c}}$ and $\mathrm{G}_{\mathrm{c}}$ data but reduced the thermal stability. The presence of nitrogen in the urethane linkages supported the charring of VEUH.

\section{ACKNOWLEDGEMENT}

The authors are thankful to Dr. K. Czifrák (University Debrecen, Hungary) for the interpretation of the NMR spectra.

\section{REFERENCES}

1. Montero de Espinoza, L. and Meier, M. A. R. Eur. Polym. J. 47, (2011) 837.

2. Khot S.N., Lascala J.J., Can E., Morye S.C., Williams G.I., Palmese G.R., Kusefoglu S.H. and Wool R.P. J. Appl. Polym. Sci. 82, (2001) 703. 
3 Lu Y. and Larock R.C. Chem. Sus. Chem. 2, (2009) 136.

4 O'Donnell A., Dweib M.A. and Wool R.P. Compos. Sci. Technol. 64, (2004) 1135.

5 Tan S.G. and Chow W.S. J. Am. Oil. Chem. Soc. 88, (2011) 915.

6 Supanchaiyamat N., Shuttleworth P.S., Hunt A.J., Clark J.H. and Matharu A.S. Green Chem. 14, (2012) 1759.

7 Uyama H., Kuwabara M., Tsujimoto T., Nakano M., Usuki A. and Kobayashi S. Chem. Mater. 15, (2003) 2492.

8 Liu Z. and Erhan S.Z. Mater. Sci. Eng. A 483-484, (2008) 708.

9 Karger-Kocsis J., Grishchuk S., Sorochynska L. and Rong M.Z. Polym. Eng. Sci. 54, (2014) 747.

10 Tan S.G. and Chow W.S. J. Thermal. Anal. Calorim. 101, (2010) 1051.

11 Tsujimoto T., Ohta E. and Uyama H. Express Polym. Lett. 9, (2015) 757.

12 Saithai P., Lecomte J., Dubreucq E. and Tanrattanakul V. Express Polym. Lett. 7, 2013) 910.

13 Mustapha S.N.H., Rahmat A.R. and Arsad A. Rev. Chem. Eng. 30, (2014) 167.

14 Thielemans W., McAninch I.M., Barron V., Blau W.J. and Wool R.P. J. Appl. Polym. Sci. 98, (2005) 1325.
15 Bonnaillie L.M. and Wool R.P. $J$. Appl. Polym. Sci. 105, (2007) 1042.

16 Fu L., Yang L., Dai C., Zhao C. and Ma L. J. Appl. Polym. Sci. 117, (2010) 2220.

17 Beach E.S., Cui Z., Anastas P.T., Han M. and Wool R.P. Appl. Sci. 3, (2013) 684

18 Qiu J.F., Zhang M.Q., Rong M.Z., Wu S.P. and Karger-Kocsis J. J. Mater. Chem. A. 1, (2013) 2533.

19 Rana A. and Evitts R.W. J. Appl. Polym. Sci. 132, (2015) 41807.

20 Spārninš E., Nyström B. and Andersons J. Int. J. Adhesion and Adhesives 36, (2012) 39.

21 Boyd S.E., La Scala J.J. and Palmese G.R. J. Appl. Polym. Sci. 108, (2008) 3495.

22 Campanella A., La Scala J.J. and Wool R.P. Polym. Eng. Sci. 49, (2009) 2384.

23 Grishchuk S. and Karger-Kocsis J. Express Polym. Lett. 5, (2011) 2.

$24 \mathrm{Lu}$ J., Khot S. and Wool R.P. Polymer 46, (2005) 71.

25 Jost N. and Karger-Kocsis J. Polymer 43, (2002) 1383.

26 Karger-Kocsis J. and Gryshchuk O. J. Appl. Polym. Sci. 100, (2006) 4012.
27 Corobea M.-C., Donescu D., Grishchuk S., Castella N., Apostolov A.A. and Karger-Kocsis J. Polym. Polym. Compos. 16, (2008) 547.

28 Gryshchuk O., Karger-Kocsis J., Thomann R., Kónya Z. and Kiricsi I. Composites A 37, (2006) 1252.

29 Grishchuk S. and Karger-Kocsis J. J. Mater. Sci. 47, (2012) 3391.

30 Manthey N.W., Cardona F., Francucci G. and Aravinthan T. $J$. Compos. Mater. 48, (2014) 1611.

31 Praharaj A., Behera D, Bastia D.K. and Rout A.K. Am. J. Polym. Sci. Eng. 3, (2015) 201400587 (12 pp).

32 Paramarta A., Pan X. and Webster D.C. Radtech Report (2013) (1), 26.

33 Senger J.S., Yilgor I. and McGrath J.E. J. Appl. Polym. Sci. 38, (1989) 373.

34 Karger-Kocsis J. and Friedrich K. Compos. Sci. Techn. 48, (1993) 263.

35 Karger-Kocsis J. and Gremmels J. $J$. Appl. Polym. Sci. 78, (2000) 1139.

36 Hull T.R., Kandola B.K. (eds.): Fire Retardancy of Polymers: New Strategies and Mechanisms, RSC Publ., Cambridge, UK, (2009). 